\title{
STRATEGI PENGEMBANGAN EKOWISATA MELALUI KONSEP COMMUNITY BASED TOURISM (CBT) DAN MANFAAT SOSIAL DAN EKONOMI BAGI MASYARAKAT DI DESA WISATA NGLANGGERAN, PATUK, GUNUNG KIDUL
}

\author{
Ismi Atikah Jamalina, Dyah Titis Kusuma Wardani \\ Fakultas Ekonomi Universitas Muhammadiyah Yogyakarta \\ Jl. Lingkar Selatan, Tamantirto, Kasihan, Bantul \\ Daerah Istimewa Yogyakarta 55184 \\ Email Korespondensi: ismiatikah6@gmail.com
}

Naskah Diterima: Januari 2017; Disetujui: April 2017

\begin{abstract}
This study aims to determine the socio-economic benefits of CBT concept application, as well as the extent to which the successful implementation of Community Based Tourism (CBT) concept in Nglanggeran Tourism Village and what are the strategies needed for the development of Nglanggeran Tourism Village. Data collection techniques using literature study and interview respondents in Nglanggeran. Based on the level of achievement of all the indicators above, it can be said that the application of the concept of Community Based Tourism has been successfully developed in Nglanggeran Tourism Village, Kecamatan Patuk, Kabupaten Gunung Kidul. The biggest obstacle factor is derived from the price factor, place, human resources, place and promotion. Tourism development strategy is done by overcoming the existing obstacle factors.
\end{abstract}

Kata Kunci: community based tourism, tourism village

JEL Classification: Z32, Z33, Z38

Abstrak: Penelitian ini bertujuan untuk mengetahui manfaat sosial ekonomi dari penerapan konsep CBT, serta sejauh mana keberhasilan penerapan konsep Community Based Tourism (CBT) pada Desa Wisata Nglanggeran dan apa saja strategi yang diperlukan untuk pengembangan Kawasan Desa Wisata Nglanggeran. Teknik pengumpulan data menggunakan studi literatur dan wawancara responden di Nglanggeran. Berdasarkan tingkat ketercapaian seluruh indikator diatas, dapat dikatakan bahwa penerapan konsep Community Based Tourism telah berhasil dikembangkan pada Desa Wisata Nglanggeran, Kecamatan Patuk, Kabupaten Gunung Kidul. Faktor penghambat terbesar berasal dari faktor sebagai berikut berasal dari faktor harga, tempat, sumber daya manusia, tempat dan promosi. Strategi pengembangan pariwisata dilakukan dengan mengatasi factor hambatan yang ada.

Keywords: pariwisata berbasis masyarakat, desa wisata Klasifikasi JEL: Z32, Z33, Z38 


\section{PENDAHULUAN}

Pariwisata merupakan sektor yang paling dinamis di berbagai negara. Terutama di negara-negara berkembang, pariwisata merupakan salah satu sektor terbesar penyumbang devisa negara. Dalam peraturan Undang-Undang No.10 tahun 2009 tentang Kepariwisataan pasal 4 menyatakan bahwa pariwisata bertujuan untuk meningkatkan pertumbuhan ekonomi, kesejahteraan masyarakat, menghapus kemiskinan, mengatasi pengangguran, melestarikan alam dan sumber daya, dan memajukan kebudayaan. Sektor pariwisata diharapkan dapat menghasilkan multiplier effect yang tinggi dalam perekonomian melebihi sektor-sektor unggulan lain.

Disamping dampak-dampak positif tersebut, sektor pariwisata juga mempunyai sisi lain yang sifatnya negatif. Seperti tingginya kesenjangan antara pendapatan masyarakat yang tinggal dekat dengan daerah tujuan wisata (DTW) dan yang berada jauh dari daerah tujuan wisata (DTW), hilangnya kontrol masyarakat terhadap sumberdaya ekonomi, dan sebagainya. Adanya dampak negatif yang terjadi karena adanya pengembangan sektor pariwisata mendorong semua pihak untuk memiliki kepedulian terhadap pengembangan sektor pariwisata yang lebih terkonsep.

Kesadaran ini yang mendorong pemerintah mencari konsep pengembangan wisata baru yang berorientasi pada nilai-nilai pelestarian lingkungan dan budaya masyarakat, termasuk didalamnya memberikan keuntungan jangka panjang, maka konsep pariwisata berbasis masyarakat (Community Based Tourism) diharapkan menjadi solusi dalam permasalahan ini. Keterlibatan langsung masyarakat dalam pengelolaan, dan pengembangan daerah tujuan wisata (DTW) diharapkan akan menjadi lahan yang mampu menyerap lapangan kerja serta peningkatan pendapatan masyarakat serta diharapkan mampu mengentaskan kemiskinan.

Daerah Istimewa Yogyakarta merupakan salah satu provinsi yang memiliki jumlah kunjungan wisatawan terbanyak sejak 5 tahun terakhir. DIY selalu berupaya mengembangkan berbagai potensi yang ada demi mencapai target sebagai daerah tujuan wisata utama di Jawa Tengah. Salah satu kabupaten yang sedang gencar mempromosikan pariwisatanya adalah Kabupaten Gunung Kidul. Kabupaten ini merupakan daerah yang wilayahnya paling luas diantara 5 kabupaten yang ada di DI Yogyakarta, namun berpendapatan paling rendah dan tergolong tertinggal. Gunung Kidul dikenal sebagi daerah yang tandus dengan lahan yang didominasi perbukitan kapur. Namun disisi lain Gunung Kidul dianugrahi sumberdaya alam yang luar biasa berupa kenampakan alam yang tidak dimiliki daerah lain. Wisata yang ditawarkan di Kabupaten ini sangatlah beragam, mulai dari wisata alam, wisata bahari, dan wisata budaya. Kabupaten Gunung Kidul mempunyai slogan HANDAYANI yang merupakan singkatan dari (Hijau - Aman - Normatif - Dinamis - Yakin Asah Asih Asuh - Nilai Tambah - Indah) mulai menata diri dan mempromosikan daerahnya lewat berbagai objek wisata yang kebanyakan merupakan wisata berbasis alam. Gunung Kidul mendapatkan predikat sebagai daerah salah satu daerah pariwisata terpopuler di Indonesia yang mampu memberikan kontribusi terhadap pendapatan daerah.

Berikut merupakan data jumlah kunjungan wisatawan yang berkunjung ke Gunung Kidul dalam kurun waktu 5 tahun terakhir.

Tabel 1. Jumlah Kunjungan Wisatawan ke Kabupaten Gunung Kidul pada Tahun 2011-2015

\begin{tabular}{cccc}
\hline \multirow{2}{*}{ Tahun } & \multicolumn{2}{c}{ Wisatawan (orang) } & Total (orang) \\
\cline { 2 - 3 } & Mancanegara (orang) & Domestik (orang) & \\
\hline $\mathbf{2 0 1 1}$ & 1299 & 615397 & 616696 \\
\hline $\mathbf{2 0 1 2}$ & 1800 & 998587 & 1000387 \\
\hline $\mathbf{2 0 1 3}$ & 3751 & 1333687 & 1337438 \\
\hline $\mathbf{2 0 1 4}$ & 3060 & 1952757 & 1955817 \\
\hline $\mathbf{2 0 1 5}$ & 4125 & 2638634 & 2642759 \\
\hline
\end{tabular}

Sumber: Dinas Kebudayaan dan Pariwisata Gunung Kidul 
Dari data yang disajikan dalam tabel 1 jumlah kunjungan wisatawan yang berkunjung ke obejek-objek wisata yang ada di Gunung Kidul dari tahun ke tahun terus mengalami peningkatan. Pada tahun 2011 total kunjungan wisatawan adalah 616.696 wisatawan kemudian mengalami peningkatan lebih dari 4 kali lipat dalam kurun waktu 5 tahun, yaitu sebanyak 2.642.759 wisatawan. Hal ini mengindikasikan bahwa minat wisatawan untuk berkunjung ke Gunung Kidul terus mengalami peningkatan.

Salah satu destinasi wisata yang sedang diminati banyak wisatawan berkunjung ke Gunung Kidul adalah di Desa Wisata Nglanggeran yang terletak di kawasan Baturagung bagian utara Kabupaten Gunung
Kidul. Desa Wisata Nglanggeran menawarkan paket lengkap sebuah perjalanan wisata meliputi educational tourism, cultural tourism, adventure tourism, agro tourism, dan green tourism yang dikemas secara menarik oleh pihak pengelola, dalam hal ini masyarakat setempat dengan memanfaatkan daya tarik 3 destinasi unggulannya yaitu, Gunung Api Purba, Embung Nglanggeran dan Air Terjun Kedung Kandang. Desa wisata Nglangeran ini merupakan aset yang sangat potensial untuk dikembangkan guna meningkatkan pendapatan daerah dan pendapatan masyarakat sekitar. Berikut adalah data dari total kunjungan wisatawan dari tahun 2007 - 2015 yang disajikan dalam sebuah grafik.

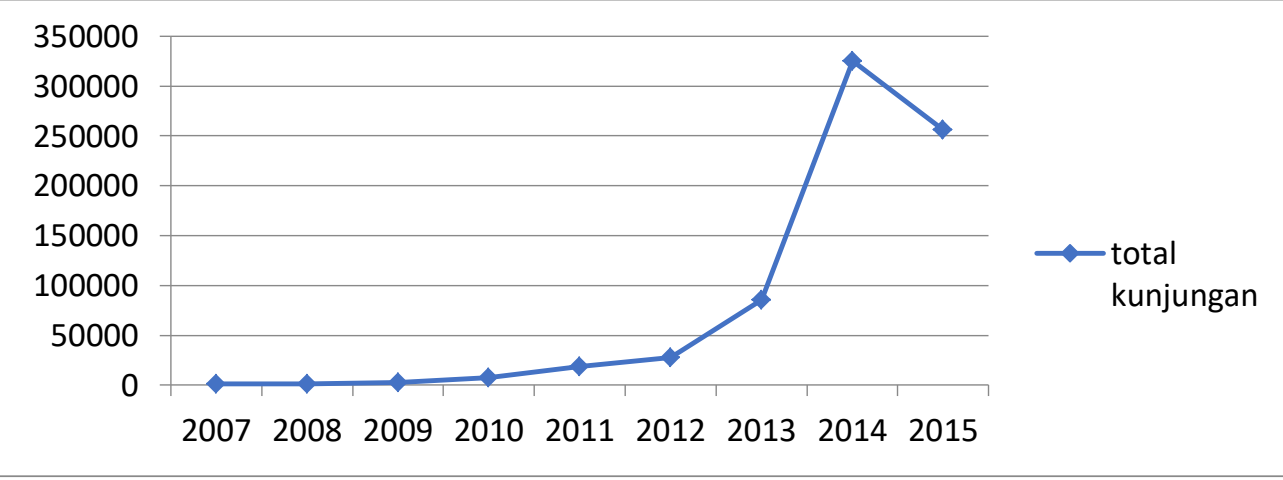

Sumber: Pengelola Ekowisata Ngalanggeran

Grafik 1. Grafik Total Kunjungan Wisatawan

Pada Gambar 2 jelas terlihat peningkatan jumlah kunjungan wisatawan sejak tahun 20072014 kemudian menunjukkan grafik menurun di tahun 2015. Dalam pengembangan destinasi wisata, terdapat beberapa masalah utama yang harus dihadapi, diantaranya perubahan iklim dan bencana alam, pemberdayaan masyarakat di daerah destinasi, kualitas SDM, serta iklim usaha yang tidak kondusif.

Dari latar belakang diatas, peneliti merumuskan masalah diantaranya apa manfaat sosial ekonomi dari penerapan konsep CBT, serta sejauh mana keberhasilan penerapan konsep CBT pada Desa Wisata Nglanggeran dan strategi apa yang diperlukan untuk pengembangan Kawasan Desa Wisata Nglanggeran.

\section{METODE PENELITIAN}

\section{Populasi dan Sampel Penelitian}

\section{Populasi}

Populasi dalam penelitian ini adalah warga yang terlibat langsung terhadap kepengelolaan Desa Wisata Nglanggeran yang berjumlah 150 jiwa (Data pengelola Desa Wisata Nglanggeran).

\section{Sampel}

Jumlah sampel yang digunakan dalam penelitian ini berjumlah 35 orang. Teknik pengambilan sampel adalah menggunakan sampling kuota. Sampling kuota adalah teknik menentukan sampel dan populasi yang mempunyai ciri tertentu sampai jumlah kuota yang diinginkan (Sugiyono, 
2007). Penentuan sampel akan dibatasi berdasarkan kriteria:

1) Warga Desa Wisata Nlanggeran yang bersedia menjadi responden

2) Warga yang terlibat langsung dalam pengelolaan Desa Wisata Nglanggeran

3) Yang membuka usaha disekitar Desa Wisata Nglanggeran

\section{Data dan Sumber Data}

Dalam penelitian ini data yang digunakan adalah data primer dan data sekunder. Data primer, yaitu data yang langsung dikumpulkan oleh peneliti dari sumber pertamanya (Suryabrata, 2006). Metode yang digunakan untuk memperoleh data primer adalah menggunakan kuisioner yang dibagikan dan diisi oleh responden, serta melalui wawancara dengan pihak pihak yang terlibat langsung dalam pengelolaan lokasi penelitian. Sedangkan data sekunder, yaitu data yang tersusun dalam bentuk dokumen-dokumen (Suryabrata, 2006). Diperoleh dari data yang ada pada pihak pengelola Desa Wisata Nglanggeran, instansiinstansi terkait seperti Dinas Kebudayaan dan Pariwisata, BPS, serta melalui studi dokumen yang ada pada penelitian sebelumnya.

\section{Lokasi Penelitian}

Penelitian akan dilakukan di Desa Wisata Nglanggeran Kecamatan Patuk Kabupaten Gunung Kidul. Lokasi dipilih karena Desa Wisata Nglanggeran merupakan salah satu desa wisata yang sudah menerapkan konsep Community Based Tourism dan pernah memenangkan penghargaan oleh Dinas Pariwisata DIY sebagai Desa Wisata dengan Keunikan Alam dalam lomba desa se-DIY pada tahun 2009. Prestasi terbaru yang diperoleh Desa Wisata Nglanggeran adalah memenangkan Award sebagai Desa Wisata Terbaik se-ASEAN pada ajang ASEAN Community Based Tourism Award yang diselenggarakan di Singapura pada tanggal 20 Januari 2017.

\section{Metode Analisis Data}

\section{Analisis Deskriptif}

Penelitian ini menggunakan analisis statistika deskriptif untuk mendeskripsiskan atau menggambarkan objek yang diteliti melalui data sampel atau populasi tanpa melakukan analisis (Sugiyono, 2007).

\section{Fishbone Analysis}

Fishbone analysis digunakan dalam upaya mengkategorikan berbagai sebab-sebab potensial dari suatu pokok masalah menggunakan cara yang mudah dimengerti dan tersusun rapi. Prosedur yang digunakan adalah terlebih dahulu menentukan problem statement yang akan menduduki posisi kepala ikan sebagai akibat yang akan dicari penyebabnya. Kemudian sepanjang ruas tulang ikan disusun main cause yang nantinya akan menjabarkan sebab-sebab lain, hingga memperoleh sebab paling potensial. Berikut gambaran diagram fishbone untuk mencari sebab akibat dibidang industri.

a. Langkah pertama, menggambar garis horizontal dan kotak didepannya yang berisi pernyataan masalah (problem statement).

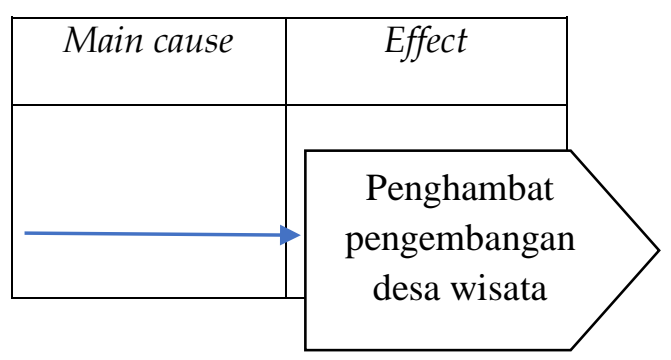

\section{Gambar 2. Langkah 1: menentukan pernyataan} masalah (problem statement)

b. Langkah kedua, menulis main cause dalam kotak yang akan dihubungkan ke garis panah utama menggunakan garis diagonal. 


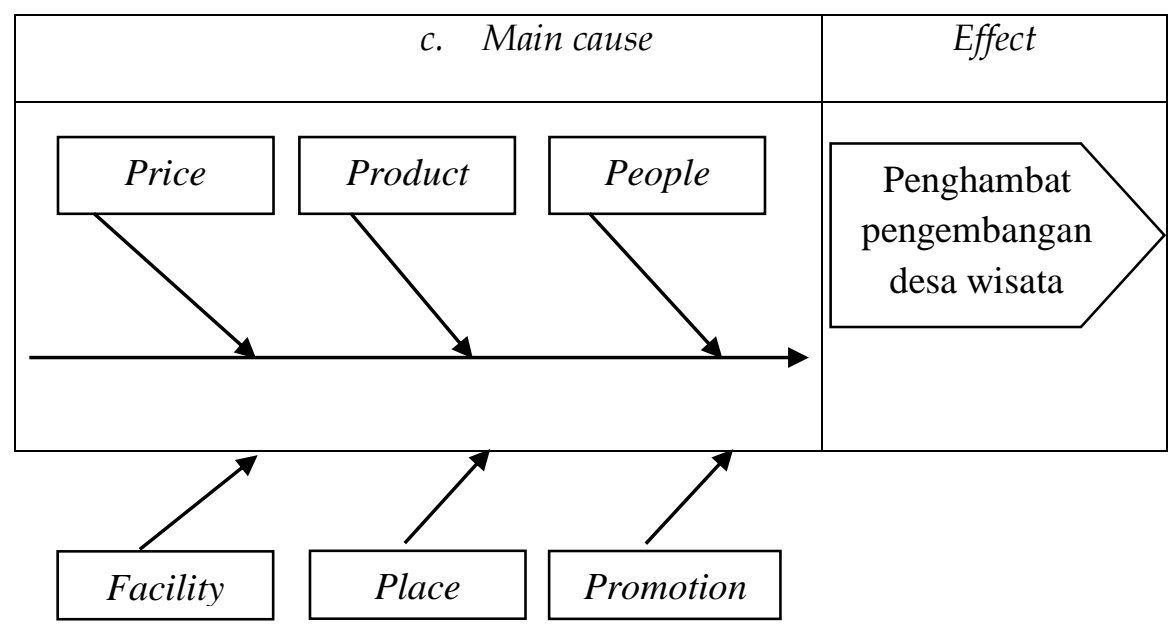

Gambar 3. Langkah 2: menuliskan main cause yang paling relevan

Ke-6 kategori ini dipilih sebagai Main cause yang menjadi faktor penghambat pengembangan Desa Wisata Nglanggeran berdasarkan penelitian terdahulu yang telah dilakukan oleh (Samaji, 2015). c. Langkah ketiga, menuliskan penyebab kecil disekitar main cause dan menghubungkannya.

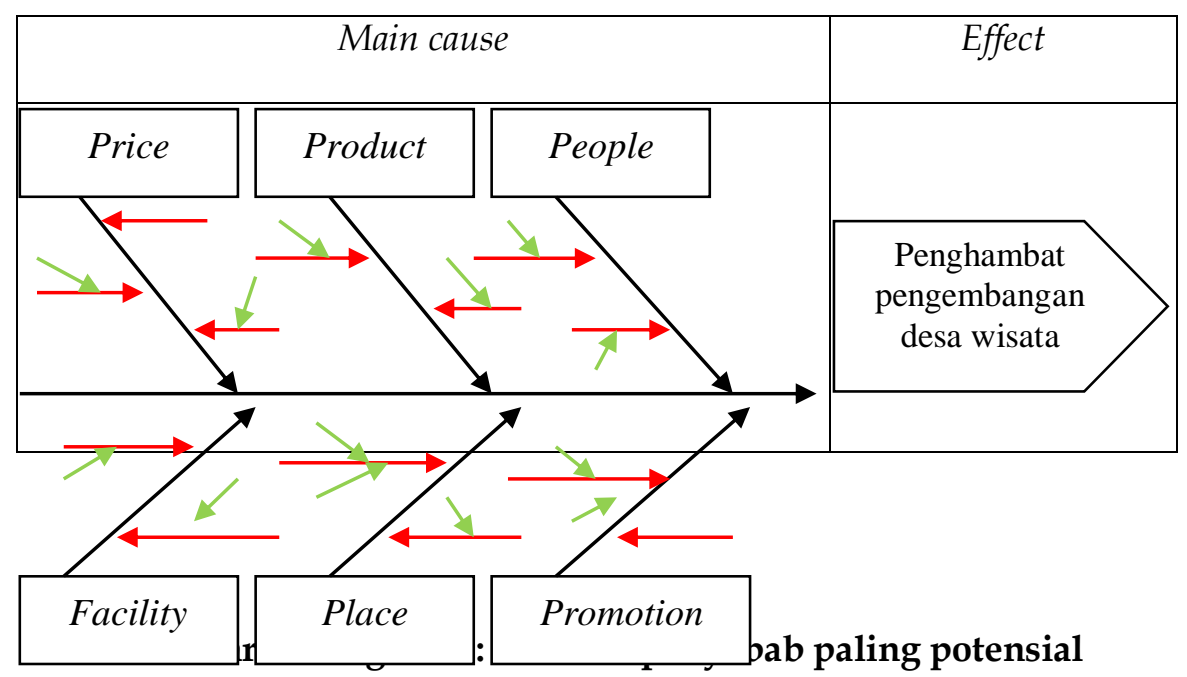

d. Setelah menemukan sebab-sebab paling Tahap terakhir adalah membuat tabel potensial dari permasalahan yang diteliti. rencana penanggulangan.

Tabel 3. Permasalahan Sebab-Akibat dan Rencana Penanggulangan

\begin{tabular}{cc}
\hline Faktor yang diamati & Masalah yang terjadi \\
\hline Price & \\
\hline People & \\
\hline Facility & \\
\hline Place & \\
\hline Promotion & \\
\hline Product &
\end{tabular}




\section{HASIL DAN PEMBAHASAN}

Identifikasi masalah penurunan jumlah kunjungan wisatawan pada tahun 2015

Upaya promosi dan perbaikan fasilitas penunjang wisata yang dikelola warga dan kelompok karang taruna Desa Wisata Nglanggeran berhasil menarik wisatawan untuk berkunjung ke Desa Wisata Nglanggeran. Namun, jumlah kunjungan wisatawan yang melonjak derastis pada tahun 2013 ke 2014 ternyata mengalami penurunan di tahun 2015. Jumlah kunjungan cenderung turun dengan selisih sebanyak 69.386 orang dengan persentase penurunan pengunjung sebanyak 21,32\% ditahun 2015. Hal ini dibenarkan oleh pihak pengelola saat sesi wawancara yang dilakukan dengan saudara Aris Budiyono, 28 tahun selaku Seksi Promosi \& Pemasaran Desa Wisata Nglanggeran.

Tabel 4. Data Jumlah Kunjungan Wisatawan pada Tahun 2012-2015

\begin{tabular}{ccccc}
\hline \multirow{2}{*}{ No } & Tahun & \multicolumn{2}{c}{ Kunjungan Wisatawan } & Total \\
\cline { 3 - 4 } & & Domestik & Mancanegara & \\
\hline $\mathbf{1}$ & 2012 & 27675 & 200 & 27875 \\
\hline $\mathbf{2}$ & 2013 & 85424 & 234 & 85658 \\
\hline $\mathbf{3}$ & 2014 & 324827 & 476 & 325303 \\
\hline $\mathbf{4}$ & 2015 & 255388 & 529 & 255917 \\
\hline
\end{tabular}

Sumber: Pengelola Desa Wisata Nglanggeran

Penurunan jumlah kunjungan wisatawan pada tahun 2014 ke 2015 yang tergolong drastis ini ditanggapi secara santai oleh pihak pengelola, bahkan menurut narasumber (Budiyono, 2016) menyatakan penurunan jumlah kunjungan wisatan ditahun 2015 sama sekali tidak mengurangi omset yang masuk kepihak pengelola. Beliau mengatakan: "Tahun 2015 itu jumlah kunjungan turun mbak, tapi omset naik. Konsep kita ekowisata itu pengelola lebih senang kalo jumlah kunjungan turun tapi omset kami tetap naik kok. Jadi buat apa mendatangkan orang-orang untuk berwisata disini tapi malah tingkat sampah dan kerusakan daya dukung kapasitas tidak sebanding dengan yang kita dapat. Jadi segmentasi kita ubah sekarang, tidak memburu orang untuk membeli tiket tapi lebih ke komunitas, corporate, dan perusahaan, yang mereka datang dengan jumlah sedikit tapi uangnya banyak". Pernyataan Aris Budiyono (2016) didukung dengan data peningkatan omset yang masuk ke pihak pengelola, dimana selalu terjadi peningkatan dari tahun ke tahun. Bahkan di tahun 2015 saat jumlah kunjungan mengalami penurunan, omset yang masuk ke pihak pengelola tetap naik. Berikut data omset masuk ke pihak pengelola yang disajikan pada table 5 .

Tabel 5. Kenaikan Omset Masuk

\begin{tabular}{ccl}
\hline No & Tahun & Omset Pengelolaan \\
\hline $\mathbf{1}$ & 2012 & $\operatorname{Rp~} 81.225 .000,-$ \\
\hline $\mathbf{2}$ & 2013 & $\operatorname{Rp~} 424.690 .000,-$ \\
\hline $\mathbf{3}$ & 2014 & $\operatorname{Rp~} 1.422 .915 .000,-$ \\
$\mathbf{4}$ & 2015 & $\operatorname{Rp} 1.541 .990 .000,-$ \\
\hline
\end{tabular}

Sumber: Pengelola Desa Wisata Nglanggeran

Pihak pengelola menuturkan telah meliputi (paket makrab, paket gathering, paket merubah segmentasi pasar ke komunitas- outbond, hiking, paket camping, dll). Pihak komunitas, perusahaan, kelembagaan, melalui pengelola tidak lagi menargetkan jumlah penawaran paket-paket yang ditawarkan kunjungan yang tinggi dengan berupaya 
mendatangkan banyak orang hanya untuk membeli tiket masuk ke objek wisata, namun wisatawan yang datang malah merusak sarana, meningkatnya tingkat sampah karena kebanyakan pengunjung yang datang kurang konservatif. Saat ini pihak pengelola lebih menargetkan pada jumlah kunjungan wisatawan yang sedikit namun masuk dengan uang yang banyak, karena wisatawan yang datang berkelompok tidak hanya membeli tiket masuk melainkan membeli paket-paket wisata yang ditawarkan oleh pihak pengelola.

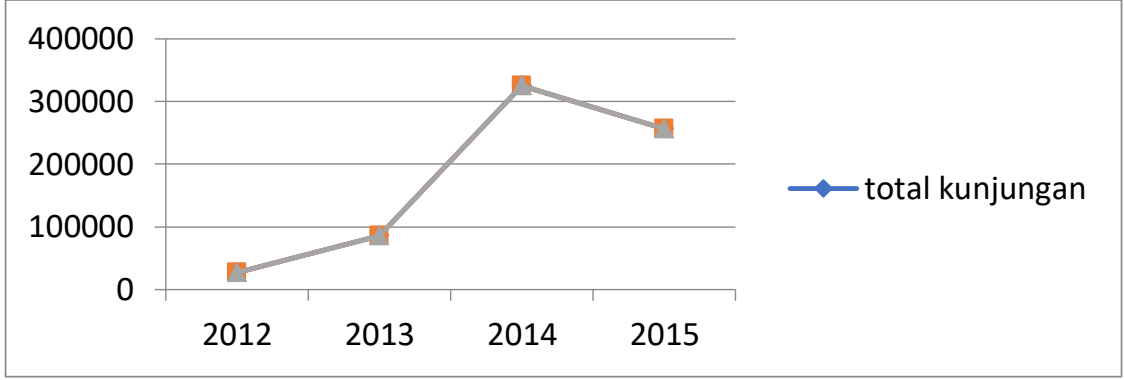

Sumber: Pengelola Desa Wisata Nglanggeran

Grafik 4. Penurunan total kunjungan

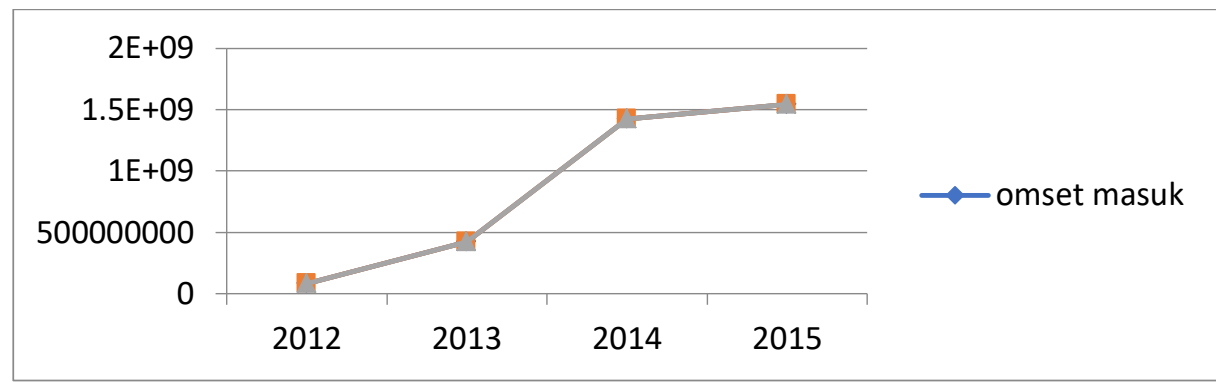

Sumber: Pengelola Desa Wisata Nglanggeran

Grafik 5. Kenaikan omset masuk

Dapat dilihat dari grafik 5 bahwa menurunnya jumlah wisatawan yang datang ke Desa Wisata Nglanggeran pada tahun 2015 tidak serta merta menurunkan omset yang masuk ke pihak pengelola. Dibuktikan dengan grafik omset masuk yang selalu meningkat dari data tahun 2012-2015.

\section{Identifikasi Manfaat Sosial Ekonomi Pengembangan Desa Wisata Nglanggeran dan melihat sejauh mana keberhasilan konsep Community Based Tourism di Desa Wisata Nglanggeran}

Identifikasi manfaat sosial-ekonomi bagi masyarakat di Desa Wisata Nglanggeran dengan adanya kegiatan wisata yang menganut konsep Community Based Tourism ini dilakukan dengan cara membagikan kuisioner pada masyarakat sebagi alat pengumpulan data. Berikut adalah hasil penelitian yang telah dilakukan oleh penulis dengan mengajukan 9 butir pertanyaan yang telah diajukan pada responden dan telah dianalisis menggunakan skala likert, sebagai berikut.

Berdasarkan hasil penelitian yang melibatkan sampel 35 responden diatas, keberaadaan Desa Wisata Nglanggeran bisa dikatergorikan SB (Sangat Berhasil) memberikan manfaat sosial ekonomi bagi masyarakat di Desa Wisata Nglanggeran, berikut total jawaban responden yang disajikan dalam grafik 6 . 


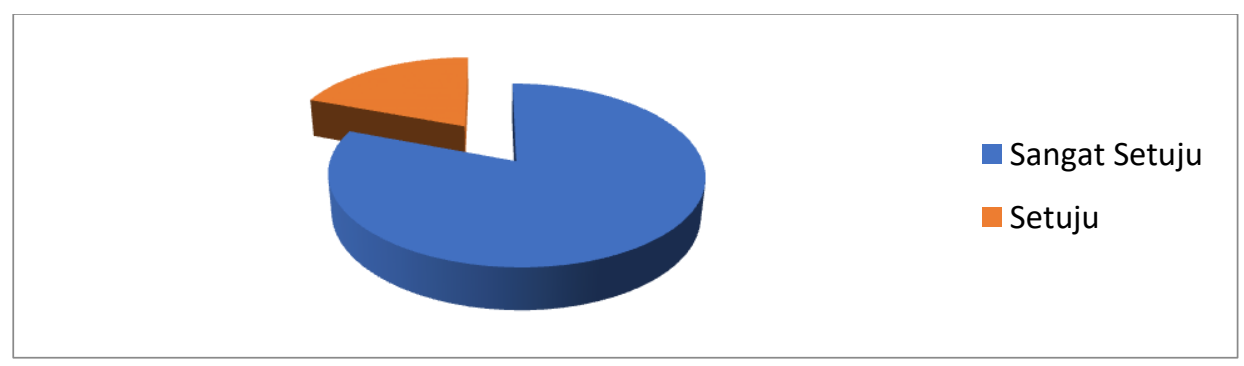

Sumber: Data primer diolah

\section{Grafik 6. Jawaban Responden}

Total jawaban SS (Sangat Setuju) berjumlah 113 atau $80,71 \%$ responden sangat setuju merasakan manfaat sosial ekonomi dari keberadaan Desa Wisata Nglanggeran ini. Sedangkan sisanya 19,28\% responden merasa setuju dengan total jawaban $S$ (Setuju) berjumlah 27 orang.

Secara keseluruhan total masyarakat yang terlibat langsung dalam pengelolaan Desa Wisata Nglanggeran adalah 154 orang. Diluar itu masih ada lagi kelompok-kelompok masyarakat yang diberdayakan dengan adanya Desa Wisata Nglanggeran ini, diantaranya:

- Kelompok homestay yang berjumlah 80-unit yang berarti memberdayakan 80 kepala keluarga.

- Kelompok ibu-ibu PKK baru 3 dari 5 dusun di Desa Wisata Nglanggeran yang terlibat dengan jumlah anggota 25 orang, memiliki bagian menurusi olahan kuliner, dan kerajinan sebagai daya tarik buatan.

- Kelompok kambing, melibatkan kurang lebih 60 anggota yang dibagi menjadi 3 kelompok.

- Kelompok pedagang yang melibatkan 16 anggota.

Tercapainya indikator-indikator sosial ekonomi sebagai aspek utama pengembangan konsep Community Based Tourism yang ada di Desa Wisata Nglanggeran meliputi:

- Adanya dana pengembangan komunitas melalui omset yang didapat pengelola.

- Terciptanya lapangan pekerjaan
- Adanya pendapatan masyarakat dari sektor pariwisata karena terbukanya ruang usaha baru.

- Meningkatkan kualitas hidup karena meningkatnya pendapatan masyarakat lewat adanya kegiatan kepariwisataan di Desa Wisata Nglanggeran.

- Menanamkan rasa bangga terhadap desanya

- Pembagian tugas laki-laki dan perempuan sesuai porsinya masing-masing.

- Memberikan ruang bagi generasi tua dan tua untuk bekerjasama dalam proses pengembangan, dan bersama-sama menjalankan kegiatan kepariwisataan di Desa Wisata Nglanggeran.

- Membangun kekuatan organisasi komunitas, seperti POKDARWIS Karang Taruna Desa Nglanggeran.

- Meningkatnya kesadaran masyarakan untuk lebih konservatif terhadap lingkungan.

Berdasarkan tingkat ketercapaian seluruh indikator diatas, dapat dikatakan bahwa penerapan konsep Community Based Tourism telah berhasil dikembangkan pada Desa Wisata Nglanggeran, Kecamatan Patuk, Kabupaten Gunung Kidul.

\section{Strategi Pengembangan Kawasan Desa Wisata Nglanggeran}

\section{Analysis Sebab-Akibat (Fishbone Analysis)}

Berdasarkan hasil wawancara yang dilakukan dengan pihak pengelola, maka diperolah beberapa masalah yang diduga menjadi faktor-faktor penghambat pengembangan Desa Wisata Nglanggeran. 
Tabel 4. Permasalahan Sebab Akibat

\begin{tabular}{|c|c|}
\hline $\begin{array}{c}\text { Faktor yang } \\
\text { diamati }\end{array}$ & Masalah yang terjadi \\
\hline Price & $\begin{array}{l}\text { C1. Tarif restribusi yang ditetapkan pemerintah terlalu tinggi } \\
\text { C2. Harga produk olahan makanan masih terlalu mahal } \\
\text { C3. Harga kuliner dan kerajinan belum sesui kualitas } \\
\text { C4. Harga paket wisata yang ditawarkan tidak sesuai dengan fasilitas yang } \\
\text { disediakan }\end{array}$ \\
\hline Product & $\begin{array}{l}\text { C1. Produk olahan yang ditawarkan kurang variatif } \\
\text { C2. Atraksi budaya tidak mempunyai jadwal yang pasti } \\
\text { C3. Paket-paket wisata yang ditawarkan desa wisata nglanggeran kurang menarik }\end{array}$ \\
\hline People & $\begin{array}{l}\text { C1. Wisatawan yang datang kurang konservatif } \\
\text { C2. Kurangnya SDM yang profesional dalam pengelolan Desa Wisata Nglanggeran } \\
\text { C3. SDM kurang kreatif dalam memproduksi olahan khas } \\
\text { C4. SDM yang ada minim yang mampu berbahasa asing } \\
\text { C5. SDM kurang Ramah }\end{array}$ \\
\hline Facility & $\begin{array}{l}\text { C1. Ketersedian lahan parkir belum memadai } \\
\text { C2. Jumlah homestay terlalu sedikit } \\
\text { C3. Dibeberapa titik, jalanan menuju objek wisata terlalu curam atau licin } \\
\text { C4. Sinyal buruk untuk beberapa provider }\end{array}$ \\
\hline Place & $\begin{array}{l}\text { C1. Daya tarik wisata sangat dipengaruhi oleh cuaca } \\
\text { C2. Lokasi desa nglanggeran rawan tanah longsor } \\
\text { C3. Lahan yang tersedia kurang memadai }\end{array}$ \\
\hline Promotion & $\begin{array}{l}\text { C1. Promosi masih menggunakan bahasa Indonesia } \\
\text { C2. Kurang kerjasama dengan pihak pengembang } \\
\text { C3. Kurang memanfaatkan media sosial } \\
\text { C4. Pihak pengelola kesulitan untuk memasarkan paket wisata pada wisatawan }\end{array}$ \\
\hline
\end{tabular}

Sumber: Data Primer

Dapat diketahui faktor-faktor penghambat pengembangan Desa Wisata Nglanggeran, yaitu dari segi price (harga), product (produk), people (SDM), facility (fasilitas), place (lokasi), dan promotion (promosi). Setelah melalui sesi jejak pendapat menggunakan alat bantu kuisioner serta sesi yang telah dibagikan pada responden, kemudian ditemukan faktor paling dominan sebagai penghambat pengembangan Desa Wisata Nglanggeran. Berikut rincian masalah tersebut:

Tabel 6. Faktor Penghambat Paling Dominan

\begin{tabular}{|c|l|c|}
\hline Main Cause & \multicolumn{1}{|c|}{$\begin{array}{c}\text { Faktor Penghambat Paling } \\
\text { Dominan }\end{array}$} & Grade \\
\hline Product & $\begin{array}{l}\text { Kurang mengoptimalkan hasil } \\
\text { olahan kuliner yang berbahan } \\
\text { dasar singkong, coklat, pisang, } \\
\text { dan susu kambing. }\end{array}$ & Menghambat \\
\hline Place & $\begin{array}{l}\text { Wisata berbasis alam sangat } \\
\text { dipengaruhi cuaca }\end{array}$ & Menghambat \\
\hline
\end{tabular}




\begin{tabular}{|c|l|c|}
\hline Main Cause & \multicolumn{1}{|c|}{$\begin{array}{c}\text { Faktor Penghambat Paling } \\
\text { Dominan }\end{array}$} & Grade \\
\hline People & $\begin{array}{l}>\text { Wisatawan yang datang } \\
\text { kurang konservatif } \\
\text { SDM minim yang mampu } \\
\text { berbahasa asing }\end{array}$ & Sangat menghambat \\
\hline Facility & $\begin{array}{l}\text { Ketersediaan lahan parkir sangat } \\
\text { minim, serta akses jalan terlalu } \\
\text { sempit. }\end{array}$ & Menghambat \\
\hline Promotion & $\begin{array}{l}>\text { Promosi masih menggunakan } \\
\text { bahasa Indonesia } \\
\text { Kurang promosi objek Air } \\
\text { Terjun Kedung Kadang }\end{array}$ & Menghambat \\
\hline
\end{tabular}

Sumber: Data primer diolah

\section{Rencana Penanggulangan Masalah}

Setelah mengetahui faktor penyebab yang paling dominan terhadap permasalahan, langkah selanjutnya yaitu menentukan rencana penanggulangan untuk mengurai permasalahan yang ada. Adapun strategi yang akan dilakukan adalah:

a. Price (harga)

Price (harga) dimasukan dalam kategori Main Cause pada penelitian ini, dikarenakan mewakili pendapat dari sejumlah wisatawan yang merasa keberatan dengan harga tiket masuk kawasan objek wisata yang dirasa terlalu mahal bagi sebagian wisatawan. Namun sejauh penelitian dilapangan, harga tidak terlalu menjadi faktor dominan yang menghambat pengembangan Desa Wisata Nglanggeran. Berdasarkan hasil wawancara dengan pihak pengelola, harga tiket masuk sengaja dinaikan sebagai upaya mengontrol jumlah kunjungan wisatawan agar tidak terlalu banyak. Hal ini sengaja dilakukan untuk mengembalikan konsep ekowisata yaitu perjalanan wisata sekaligus menjaga kelestarian alam, sehingga dengan menaikan harga tiket diharapkan akan mendatangkan wisatawan yang lebih konservatif agar ekosistem tetap terjaga.

b. Product (Produk)
Sejauh ini sudah terdapat beberapa produk olahan kuliner di Desa Wisata Nglanggeran diantaranya: dodol kakao, kopi kakao, brownis singkong. Sedangkan untuk olahan susu, terdapat minuman susu rasa coklat, dan permen susu. Untuk menanggulangi permasalahan kurang variatifnya olahan produk kuliner di Desa Wisata Nglanggeran sedangkan ketersediaan bahan baku utama seperti kakao, pisang, singkong, dan susu kambing cukup melimpah. Pengelola dapat mengolah bahan baku tersebut menjadi es krim yang bahan baku utama nya menggunakan susu kambing, kemudian memberi varian rasa coklat dan pisang yang bahan bakunya banyak terdapat di Desa Wisata Nglanggeran. Es krim ini dapat dikemas dalam cup-cup kecil, kemudian dibekukan dalam lemari es agar tahan lama.

c. People (SDM)

Wisatawan kurang konservatif merupakan salah satu faktor penghambat pengembangan ekowisata. Beberapa tahun terakhir, review di media sosial tentang keindahan 3 objek wisata yang ada di Desa Wisata Nglanggeran khususnya Gunung Api Purba dan Embung Nglanggeran cenderung meningkatkan kunjungan wisatawan. Namun, kunjungan wisatawan yang kurang konservatif malah 
meningkatkan kerusakan lingkungan serta meningkatkan jumlah sampah yang ada. Pengelola telah berupaya menanggulangi permasalahan tersebut lewat penyediaan papan informasi tentang larangan merusak lingkungan dengan kata-kata yang kekinian. Selain itu pengelola perlu lebih banyak menyediakan tempat sampah dibeberapa titik agar dapat menampung sampah wisatawan.

Selain itu, masalah internal pengelola yang masi sangat minim dalam berbahasa asing sedangkan Desa Wisata Nglanggeran mulai memasuki pasar Internasional melalui keterlibatan Gunung Api Purba dalam Global Geopark sangat menghambat pengembangan Desa Wisata Nglanggeran. Sejauh ini pihak pengelola memang menyediakan tour guide bagi para wisatawan asing yang memerlukan. Selain itu, beberapa pelatihan Bahasa Inggris pernah diikuti oleh anggota. Namun, usaha tersebut kurang berhasil karena kedatangan wisatawan asing yang tidak menentu membuat para pengelola jarang mempraktekan kemampuan berbahasa asingnya sehingga cenderung kembali lupa. Harapan dari pihak pengelola adalah kerjasama dan pendampingan dari pihak universitas-universitas untuk memberikan pelatihan bahasa asing secara berkelanjutan dan terjadwal dengan mendatangkan staf pengajar secara teratur agar kemampuan berbahasa asing pengelola terus terasah. Sedangkan untuk rencana penanggulangan jangka pendek, para anggota yang sama sekali belum bisa berbahasa asing minimal mengetahui kosa kata sederhana untuk percakapan yang dapat dipelajari lewat kamus kamus bahasa asing.

d. Place (lokasi)

Konsep wisata berbasis alam memang sangat dipengaruhi oleh cuaca. Sehingga untuk memberikan kenyamanan bagi wisatawan pengelola perlu menyediakan lebih banyak lagi gazebo dibeberapa titik sebagai tempat berteduh bagi wisatawan.

e. Facility (fasilitas)

Faktor dominan yang menjadi penghambat dari sisi fasilitas adalah ketersediaan lahan parkir yang masi minim belum mampu menampung kendaraan wisatawan dalam jumlah banyak. Akses jalan yang terlalu sempit sehingga tidak bisa dilewati mobil besar. Harapan dari pihak pengelola adalah agar segera dibangun terminal untuk memudahkan akses dan memudahkan penjemputan bagi wisatawan yang membutukan angkutan lokal menuju lokasi. Kemudian jika sudah tersediannya terminal diharapkan para wisatawan akan memilih menggunakan moda transportasi umum atau menggunakan transportasi lokal yang disediakan masyarakat jika datang dalam satu rombongan besar, sehingga lahan parkir yang minim pada lokasi desa wisata tidak lagi menjadi hambatan.

f. Promotion (promosi)

Promosi yang dilakukan desa wisata Nglanggeran sejauh ini sudah cukup baik. Dengan adanya website yang dapat diakses oleh wisatawan yaitu www.gunungapipurba.com, brosur, serta memanfaatkan media sosial seperti Instagram sebagai media promosi. Namun kendala lain yang disadari oleh pihak pengelola adalah bahasa, dengan masuknya Desa Wisata Nglanggeran sebagai Desa Wisata Terbaik se-ASEAN dan Gunung Api Purba sebagai Global Geopark. Mengharuskan pihak pengelola untuk menterjemahkan media promosi yang semula hanya berbahasa Indonesia menjadi bahasa Inggris atau mungkin berbagai bahasa lainnya. Dengan tersedianya berbagai macam pilihan bahasa pada website sebagai salah satu media promosi, memudahkan wisatawan asing untuk mengetahui lebih banyak tentang Desa 
Wisata Nglanggeran sebelum memutuskan datang untuk berkunjung.

\section{SIMPULAN}

Berdasarkan tingkat ketercapaian seluruh indikator diatas, dapat dikatakan bahwa penerapan konsep Community Based Tourism telah berhasil dikembangkan pada Desa Wisata Nglanggeran, Kecamatan Patuk, Kabupaten Gunung Kidul. Faktor penghambat terbesar berasal dari faktor sebagai berikut:

a. Sumber daya manusia yang tidak mampu berbahasa Inggris dan wisatawan yang kurang konservatif menghambat pengembangan pariwisata di Nglanggeran.

b. Dari sisi produk, kurang mengoptimalkan hasil olahan kuliner yang berbahan dasar singkong, coklat, pisang dan susu kambing yang merupakan produk andalan daerah setempat.

c. Wisata berbasis alam sangat dipengaruhi cuaca

d. Ketersediaan lahan parkir sangat minim, serta akses jalan terlalu sempit.

e. Promosi masih menggunakan bahasa Indonesia dan kurangnya promosi terhadap objek Air Terjun Kedung Kadang

Adapun strategi yang akan dilakukan adalah:

a. Price (harga)

Harga tiket masuk sengaja dinaikan sebagai upaya mengontrol jumlah kunjungan wisatawan agar tidak terlalu banyak. Hal ini sengaja dilakukan untuk mengembalikan konsep ekowisata yaitu perjalanan wisata sekaligus menjaga kelestarian alam, sehingga dengan menaikan harga tiket diharapkan akan mendatangkan wisatawan yang lebih konservatif agar ekosistem tetap terjaga.

c. Product (Produk)

Menanggulangi permasalahan kurang variatifnya olahan produk kuliner di Desa Wisata Nglanggeran karena ketersediaan bahan baku utama seperti kakao, pisang, singkong, dan susu kambing cukup melimpah.

b. People (SDM)

Kunjungan wisatawan yang kurang konservatif malah meningkatkan kerusakan lingkungan serta meningkatkan jumlah sampah yang ada.

Selain itu lemahnya sumber daya manusia dalam berbahasa Inggris mendorong pihak pengelola berharap adanya kerjasama dan pendampingan dari pihak UniversitasUniversitas untuk memberikan pelatihan bahasa asing secara berkelanjutan dan terjadwal dengan mendatangkan staf pengajar secara teratur agar kemampuan berbahasa asing pengelola terus terasah.

d. Place (lokasi)

Konsep wisata berbasis alam memang sangat dipengaruhi oleh cuaca. Sehingga untuk memberikan kenyamanan bagi wisatawan pengelola perlu menyediakan lebih banyak lagi gazebo dibeberapa titik sebagai tempat berteduh bagi wisatawan.

e. Facility (fasilitas)

Faktor dominan yang menjadi penghambat dari sisi fasilitas adalah ketersediaan lahan parkir yang masih minim belum mampu menampung kendaraan wisatawan dalam jumlah banyak. Akses jalan yang terlalu sempit sehingga tidak bisa dilewati mobil besar.

f. Promotion (promosi)

Promosi yang dilakukan Desa Wisata Nglanggeran sejauh ini sudah cukup baik. Namun kendala lain yang disadari oleh pihak pengelola adalah bahasa, dengan masuknya Desa Wisata Nglanggeran sebagai Desa Wisata Terbaik se-ASEAN dan Gunung Api Purba sebagai Global Geopark mengharuskan pihak pengelola untuk menyediakan berbagai macam pilihan bahasa pada website sebagai salah satu media promosi. Dengan demikian memudahkan wisatawan asing untuk mengetahui lebih banyak tentang Desa 
Wisata Nglanggeran sebelum memutuskan datang untuk berkunjung.

\section{DAFTAR PUSTAKA}

Administator Desa Nglanggeran. (2017). Statistik Berdasarkan Pekerjann. Dipetik Januari 31, 2017, dari Desa Nglanggeran, Patuk, Gunungkidul: http://nglanggeran-patuk.desa.id/

Ainun, N. F., Hetty, \& Darwis, S. R. (2014). Pengembangan Desa Wisata Melalui Kosep Community Based Tourism. Prosiding: Riset dan PKM, 2 (3), 301444.

Astuti, Y. D. (2010). Pemetaan Dampak Ekonomi Pariwisata Dalam Penerapan Konsep Community Based Tourism (Studi Kasus Desa Wisata Kebon Agung di Kabupaten Bantul). Fakultas Ekonomi. Surakarta: Universitas Sebelas Maret.

Budhi, S. K., \& Lestari, N. P. (2016). Community Based Ecotourism Development in Jatiluwih Village. Jurnal IJABER, 14, 1865-1880.

Budiyono, A. (2016, Oktober 22). Penurunana Jumlah Kunjungan. (A. I. Jamalina, Pewawancara)

Byczek, C. (2011, April). Blessing for All? Community Based Ecotourism In Bali between Global, National, and Lokal Interest- a Case Study: In ASEAS. Jurnal Article, 81-106.

Demartoto, A. D. (2008). Strategi Pengembangan Objek Wisata Pedesaan Oleh Pelaku Wisata Di Kabupaten Boyolali. Surakarta: Universitas Sebelas Maret.

Dewi, M. H. (2013). Pengembangan Desa Wisata Berbasis Partisipasi Masyarakat Lokal Di Desa Wisata Jatiluwih Tabanan, Bali. (C. Fadeli, \& M. Baiquni, Penyunt.) KAWISTARA, III, 117-226.

Fandeli, C. (2003). Pengembangan Kawasan Pedesaan Sebagai Objek WisatA
(Perencanaan Modal Kelembagaan, Pasar dan Paket Wisata Pedesaan Sekitar Gunung Merapi). Yogyakarta: Lembaga Penelitian Universitas Gajahmada.

Fauziah, N. (2009). Aplikasi Fishbone Analisis dalam Meningkatkan Produksi Teh pada PT Rumpun Sari Kemuning, Kabupaten Karang Anyar. Universitas Sebelas Maret, Fakultas Pertanian. Surakarta: Universitas Sebelas Maret.

Goodwin, H., \& Santilli, R. (2009). Community Based Tourism: Success? ICRT Occasional Paper 11.

Hariadi, Dodi; Koordinator Statistik Kec. Patuk. (2015, Oktober). STATISTIKA DAERAH KECAMATAN PATUK 2015. Dipetik November 27, 2016, dari Badan Pusat Statistik Kabupaten Gunungkidul: http:/ / gunungkidulkab.bps.go.id

Hariadi, Dodi; Koordinator Statistik Kec. Patuk. (2016, September). STATISTIKA DAERAH KECAMATAN PATUK 2016. Dipetik November 27, 2016, dari Badan Pusat Statistik Kabupaten Gunungkidul:

http://gunungkisulkab.bps.go.id

Kerjasama Direktorat Produk Pariwisata. (2009). Prinsip dan Kriteria Ekowisata Berbasis Masyarakat. Departemen Kebudayaan dan Pariwisata; WWFIndonesia. Direktorat Jendral Pengembangan Destinasi Pariwisata.

Kho, B. (2016, Juni 27). Pengertian Cause and Effect Diagram (Fishbone Diagram) Cara Membuatnya. Dipetik November 30, 2016, dari Ilmu Managmen Industri: http:/ / ilmumanagmenindustri.com

Kiss, A. (2004). Is Community Based Ecotourism a Good Use of Biodiverencity Concervation Funds? Opinion, 19, 232-237.

Koordinator Statistik Kec. Patuk. (2014, Desember). KECAMATAN PATUK DALAM ANGKA 2014. (S. N. Gunungkidul, Penyunt.) Dipetik 
November 27, 2016, dari Badan Pusat Statistik Kabupaten Gunungkidul: http://gunungkidulkab.bps.go.id

Koordinator Statistik Kec. Patuk. (2015, November). KECAMATAN PATUK DALAM ANGKA 2015. (S. N. Gunungkidul, Penyunt.) Dipetik November 27, 2016, dari Badan Pusat Statistik Kabupaten Gunungkidul: http://gunungkidulkab.bps.go.id

Koordinator Statistik Kec. Patuk. (2016, Juli). KECAMATAN PATUK DALAM ANGKA 2016. Dipetik November 27, 2016, dari Badan Pusat Statistik Kabupaten Gunungkidul: http://gunungkidul.bps.go.id

Kurniawan, W. (2015). Dampak Sosial Ekonomi Pembangunan Pariwisata Umbul Sidomukti Kecamatan Bandungan Kabupaten Semarang. Fakultas Ekonomi. Semarang: Universitas Negeri Semarang.

Lucchetti, V. G., \& Font, X. D. (2013, June). Community Based Tourism: Critical Success Factors. Dipetik November 27, 2016, dari The International Centre for Responsible Tourism: http://www.icrtourism.org

Manahampi, R. M. (2015). Peranan Ekowisata Bagi Kesejahteraan Masyarakat Bahoi Kecamatan Likupang Barat. (L. Rengkung, Y. Rori, \& J. Timban, Penyunt.) II, 1-18.

Melantino, A. R. (2013). Analisis Dampak Ekonomi Objek Wisata Terhadap Pendapatan Masyarakat Lokal (Tanam Nasional Tiga Puluh Kabupaten Indragiri Hulu). Jurnal Ekonomi, 1;17.

Murti, B. (2013). Desain dan Ukuran Sample Untuk Penelitian Kuantitatif dan Kualitatif di Bidang Kesehatan. Yogyakarta: Gajah Mada Univertisy Press.

Nitikasetsoontorn, S. (2014, Juli). The Succes Factor of Community Based Tourism in Thailand. Dissertation.
Poerwanto, G. H. (2014, April 27). Diagram Fishbone. Dipetik November 16, 2016, dari Managmen Kualitas: https:// sites.google.com

Putri, J. P., \& Manaf, A. (2013). Faktor-Faktor Keberhasilan Pengembangan Desa Wisata di Dataran Tinggi Dieng. Jurnal Teknik PWK, 2, 559-568.

Roscoe. (1982). Research Methods for Business. Dalam Sugiyono, Statistika (hal. 74). Bandung: CV ALFABET.

Samaji, R. (2015). Strategi Pengembangan Ekowisata Nglanggeran dalam Upaya Meningkatkan Pendapatan Masyarakat Desa Nglanggeran Kecamatan Patuk Kabupaten Gunungkidul. Universitas Muhammadiyah Yogyakarta, Ekonomi. Yogyakarta: Universitas Muhammadiyah Yogyakarta.

Sastrayuda, G. S. (2010). Konsep Pemberdayaan Masyarakat Berbasis Pariwisata (Community Based Tourism). Hand Out.

Sastrayuda, G. S. (2010). Konsep Pengembnagan Desa Wisata. Hand Out. Spillane, J. J. (1987). Ekonomi Pariwisata Sejarah Dan Prospeknya. Yogyakarta: Kanisius.

Statistik Desa Nglanggeran. (2017). Statistik Berdasarkan Jenis Kelamin. Dipetik Januari 31, 2017, dari Desa Nnglanggeran Kecamatan Patuk Kabupaten Gunungkidul: http://nglanggeran-patuk.desa.id

Suansari, P. (2003). Community Based Tourism Hanbook. (B. Sewartamra, K. Momtakhob, J. Lejeune, \& P. Ricards, Penyunt.) Thailand: Responsible Ecological Social Tour (REST).

Sugiyono. (2007). Statistika Untuk Penelitian (12 ed.). Bandung: CV Alfabeta.

Suryabrata, S. B. (2006). Metodologi Penelitian (1 dan 2 ed.). Jakarta, Jakarta, Indonesia: PT. Raja Grafindo Persada. 
Sutisna, E. S. (2015). Metode Penelitian Kualitatif \& Campuran. Surakarta: UPT. Penerbit dan Percetakan UNS.

Syafi'i, M. (2015). Perencanaan Desa Wisata Dengan Pendekatan Community Based Tourism (Cbt) Di Desa Bedono, Kecamatan Sayung, Kabupaten Demak. Jurnal Ruang, I, 61-70.

Vitasurya, R. V. (2016). Local Wisdom for Suitainable Development of Rural Tourism case on Kalibiru and Lopati Village Province Daerah Istimewa Yogyakarta. Jurnal Procedia: Social and Behavior Sciences, 97-108. 